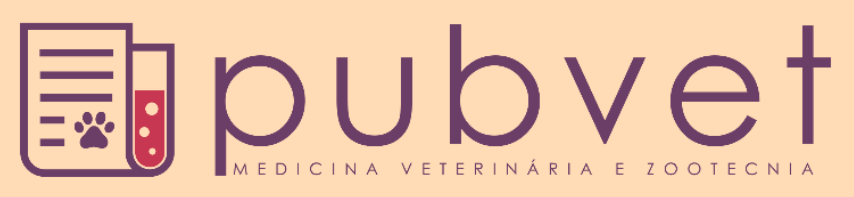

https://doi.org/10.31533/pubvet.v15n1a730.1-8

\title{
As Abelhas como modelo de estudo e ferramenta de educação ambiental no estado de Sergipe
}

\author{
Joyce Inocencia dos $\operatorname{Santos}^{10 *}$, Wilams Gomes dos $\operatorname{Santos}^{2} \bullet$, Edisio Oliveira de Azevedo ${ }^{30}$ \\ ${ }^{1}$ Graduada em Medicina Veterinária na Universidade Federal de Sergipe, São Cristóvão - Sergipe, Brasil \\ ${ }^{2}$ Professor do Instituto Federal de Sergipe, Departamento de Agroecologia, São Cristóvão - Sergipe, Brasil \\ ${ }^{3}$ Professor da Universidade Federal de Sergipe, Departamento de Medicina Veterinária São Cristóvão - Sergipe, Brasil \\ *Autor para correspondência: E-mail: joyceinocencia@gmail.com
}

Resumo. Considerando que as abelhas estão em constante ameaça por conta das ações antrópicas, foi criado em 2018 o projeto de preservação SOS ABELHAS pelo Corpo de Bombeiros do Estado de Sergipe (CBMSE) em parceria com o Instituto Federal de Sergipe (IFS), a Universidade Federal de Sergipe (UFS), apicultores e meliponicultores. Na edição de 2019 foi incorporada a utilização da educação ambiental através de um subprojeto intitulado "SOS abelhas: conhecer para preservar" que foi desenvolvido pela acadêmica Joyce Inocencia dos Santos durante o Estágio Supervisionado Obrigatório (ESO) do curso de Medicina Veterinária da Universidade Federal de Sergipe. Para tanto foram realizadas diversas palestras e oficinas abrangendo os aspectos relevantes que envolvem a vida de uma abelha, seu habitat e ações práticas que favoreçam sua manutenção no ecossistema. Deste modo, observa-se que a comunidade foi envolvida nesse processo, tomando consciência da existência e importância das abelhas, o que nos permite concluir que a educação ambiental tem um caráter multidisciplinar e que deve ser difundida por todos os profissionais que lidam com o homem, com o animal e com o ambiente.

Palavras chave: Abelhas sem ferrão, educação ambiental, polinização, preservação, resgates, SOS Abelhas

\section{Bees as a study model and environmental education tool in the state of Sergipe}

Abstract. Considering that bees are in constant threat due to anthropic actions, the SOS ABELHAS preservation project was created in 2018 by the Fire Department of the State of Sergipe (CBMSE) in partnership with the Federal Institute of Sergipe (IFS), the Federal University of Sergipe ( UFS), beekeepers and honey producers. In the 2019 edition, the use of environmental education was incorporated through a subproject entitled "SOS bees: know to preserve" that was developed by academic Joyce Inocencia dos Santos during the Mandatory Supervised Internship (ESO) of the Veterinary Medicine course at the UFS. For this purpose, several lectures and workshops were held covering the relevant aspects that involve the life of a bee, its habitat and practical actions that favor its maintenance in the ecosystem. Thus, it is observed that the community was involved in this process, becoming aware of the existence and importance of bees, which allows us to conclude that environmental education has a multidisciplinary character and that it must be disseminated by all professionals who deal with man, with the animal and with the environment.

Keywords: stingless bees, environmental education, pollination, preservation, rescues, SOS Abelhas 


\section{Las abejas como modelo de estudio y herramienta de educación ambiental en el estado de Sergipe}

Resumen. Teniendo en cuenta que las abejas están en constante amenaza debido a las acciones antrópicas, el proyecto de preservación SOS ABELHAS fue creado en 2018 por el Departamento de Bomberos del Estado de Sergipe (CBMSE) en asociación con el Instituto Federal de Sergipe (IFS), la Universidad Federal de Sergipe (UFS), apicultores y productores de miel. En la edición de 2019, el uso de la educación ambiental se incorporó a través de un subproyecto titulado "Abejas SOS: conocer para preservar" que fue desarrollado por la académica Joyce Inocencia dos Santos durante la pasantía supervisada obligatoria (ESO) del curso de Medicina Veterinaria en la Universidad Federal de Sergipe Con este fin, se realizaron varias conferencias y talleres que cubrieron los aspectos relevantes que involucran la vida de una abeja, su hábitat y acciones prácticas que favorecen su mantenimiento en el ecosistema. Por lo tanto, se observa que la comunidad estuvo involucrada en este proceso, tomando conciencia de la existencia e importancia de las abejas, lo que nos permite concluir que la educación ambiental tiene un carácter multidisciplinario y que debe ser difundida por todos los profesionales que tratan con el hombre, con el animal y con el medio ambiente.

Palabras clave: abejas sin aguijón, educación ambiental, polinización, preservación, rescates, SOS Abelhas

\section{Introdução}

Segundo a pesquisadora Alves dos Santos (2002), a diversidade de abelhas no Brasil é grande, mas pouco conhecemos sobre a vida da maioria dessas espécies, estima-se que existam mais de 5 mil espécies e pouco mais de 2 mil foram catalogadas. As abelhas precisam ser preservadas, bem como o ambiente em que vivem, pois são dependentes dele para completar seu ciclo de vida. Essa biodiversidade atualmente está sendo ameaçada por ações antrópicas, como agrotóxicos, desmatamentos, queimadas e ampliação da urbanização em regiões onde antes existia vegetação. Todos esses eventos contribuem de forma sistemática para o desaparecimento do habitat e dos ninchos ecológicos, levando consequentemente a diminuição das populações de abelhas nativas, que necessitam dessa diversidade para sobreviver.

Diante do declínio acentuado das abelhas, surge a necessidade de ações voltadas à preservação das espécies e dos habitats que se encontram. Todos os profissionais que atuam de forma direta ou indiretamente com o meio ambiente devem procurar caminhos que possam minimizar esse cenário de destruição. Uma forma eficiente de promover a consciência ambiental é por meio da educação. "Ensinar não é transferir conhecimento, mas criar as possibilidades para a sua própria produção ou a sua construção" (Freire, 1996). A educação ambiental fornece um saber ambiental materializado nos valores éticos e nas regras políticas de convívio social, implicando a relação entre benefícios e malefícios da apropriação do uso da natureza (Sorrentino et al. 2005).

Durante o estágio obrigatório (ESO) do curso de Medicina Veterinária da UFS, realizado no CBMSE, foi desenvolvido um subprojeto de educação ambiental na Escola Municipal Josefa Inocencia dos Santos, município de Areia Branca-SE, denominado "SOS ABELHAS: CONHECER PARA PRESERVAR", que consistiu em ciclos de palestras e oficinas artesanais tendo como o tema central o universo das abelhas, promovendo a consciência ecológica para preservação das espécies, dos habitats e das boas práticas agroecológicas. Diante a repercussão positiva, a estagiária foi convidada durante os quatro meses do projeto, a executá-lo de forma parcial em Escolas Municipais, Escolas Estaduais, Instituições Federais de Ensino, uma associação e uma comunidade indígena, socializando informações como ferramenta de preservação das abelhas.

\section{Material e métodos}

As ações do subprojeto foram realizadas no período de setembro a dezembro de 2019 e divididas em 7 encontros (3 palestras, 3 oficinas e o encerramento). As datas foram definidas previamente pela diretora da escola, de acordo com a programação do calendário escolar 2019. 
O primeiro encontro dia 30 de setembro de 2019 , no qual foi apresentando o todo o projeto e a primeira palestra com o tema: "O que é uma abelha?" Foram abordados os seguintes assuntos:

- Morfologia básica de uma abelha.

- Espécies de abelhas encontradas no estado.

- Medidas de prevenção ao ataque de abelhas com ferrão.

- Produtos das abelhas.

- Importância da polinização.

- Mortandade de abelhas e agrotóxicos

- Medidas de proteção ao meio ambiente.

- Medidas de proteção e ajuda às abelhas.

Material didático: Projetor de slides. Abelhas em placas de petri; Abelha Jataí feita de gesso; Flores diversas que alimentam as abelhas.

O segundo encontro para dar continuidade ao tema anterior da palestra, ocorreu dia 04 de outubro de 2019, foi realizada uma oficina com o tema: "Plantando para as abelhas". Foi levado para a sala de aula, sementes, sementeira com substrato, etiquetas de identificação e canetas marcadoras permanentes. Cada aluno recebeu seu material e após colocar seu nome na etiqueta realizou o plantio da semente no local escolhido. A planta escolhida foi a espécie trepadeira Antigonon leptopus, conhecida popularmente como Amor-agarradinho, fornecedora de pólen e néctar para as abelhas. As sementeiras foram levadas para germinar e foram entregues a cada aluno no encerramento do projeto, quatro meses depois.

O terceiro encontro foi realizado dia 08 de novembro de 2019, com a palestra de tema: "Abelhas sem ferrão". Foram abordados os seguintes assuntos:

- Principais espécies encontradas no estado de Sergipe.

- Principais características morfológicas.

- Habitas naturais de nidificação.

- Diferenças entradas dos ninhos.

- Aquisição ecologicamente correta de uma colmeia.

Material didático: Projetor de slides; Caixa didática de abelha com células de crias dispostas em discos; Caixa didática de abelha com células de crias dispostas em cachos; Loções atrativas para iscas e iscas para captura de abelhas em ferrão.

O quarto encontro foi realizado dia 14 de novembro de 2019 com a oficina "Confecção de iscas para captura de abelhas sem ferrão". Os alunos foram divididos em grupos de quatro integrantes e receberam um kit para confecção da isca que continha, uma caixa de leite vazia com tampa, um cano de plástico de $15 \mathrm{~cm}$ em curva, um saco preto, fita adesiva e $5 \mathrm{ml}$ de atrativo para abelhas sem ferrão. Cada grupo, sob orientação, montou sua isca e, ao final do processo, foi depositado e agitado na caixa de leite $5 \mathrm{ml}$ da loção atrativa [200g de cera e própolis das abelhas (Jataí e Iraí) em um 1 litro de álcool etílico a $70 \%$, maturada por mais de 6 meses]. A caixa foi devidamente identificada com os nomes dos integrantes do grupo e após decisão democrática entre eles, foi escolhido o membro que levaria a isca para instalação na mata e/ou no quintal de casa. Ficou decidido que cada grupo faria as vistorias nas suas iscas.

O quinto encontro foi realizado dia 28 de novembro de 2019, foi ministrada a terceira e última palestra com o tema: "Abelhas solitárias", com os seguintes assuntos:

- Ciclo de vida de uma abelha solitária.

- Variedade de espécies encontradas no estado.

- Tipos de nidificações na natureza.

- Nidificações em ninhos artificiais.

- Maneiras de ajudar uma abelha solitária.

Material didático: Ninhos de argila natural e queimados; Ninhos de madeira para abelhas solitárias; Folhas de Paineira (Ceiba glaziovii) cortadas por abelha do gênero Megachile. E Abelha entomológica gênero Epicharis. 
O sexto evento foi realizado dia 29 de novembro de 2019 com a realização da oficina: "Construção de ninhos de argila para abelhas solitárias". Foi entregue a cada aluno uma porção de argila previamente preparada e ferramentas (estacas) confeccionadas artesanalmente com pedaços de bambus para sua modelagem. Cada aluno criou seu ninho seguindo sua criatividade e sob as orientações recomendadas para ninhos das espécies de abelhas solitárias. Ao final da oficina, as peças de argila foram armazenadas num local para secagem.

O sétimo e último encontro foi realizado dia 19 de dezembro de 2019, concluindo o projeto de quatro meses de duração. Foi montada uma exposição com o material confeccionado nas três oficinas, com mudas de várias espécies de árvores para doação e três banners com fotos dos encontros anteriores.

Cada aluno foi chamado individualmente para receber:

- Sua muda plantada na primeira oficina.

- Seu ninho de argila confeccionado na última oficina.

- Uma sacola de brinde contendo: Garrafa de $80 \mathrm{~g}$ de mel de Apis, Sacola de balas de mel, folder sobre polinização.

\section{Resultados e discussão}

As palestras realizadas durante o ESO tiveram como principal objetivo a propagação de informações sobre as espécies abelhas, tanto das abelhas sociais (Ápis e ASF) quanto das abelhas solitárias. Foram elaboradas para o ensino fundamental com uma linguagem acessível, com várias ilustrações (fotos e desenhos) para que a fixação do conhecimento fosse assimilada de forma eficaz.

A primeira palestra na escola municipal de Areia Branca do subprojeto SOS Abelhas ocorreu no dia 30/09/19 para quatro turmas do $5^{\circ}$ ano do ensino fundamental menor (Figuras 1). Foi apresentado todo o projeto SOS abelhas e a palestra cujo tema foi “O que é uma abelha?". Na medida em que o tema foi desenvolvido, notava-se, diante da atenção requerida, dos olhos fixos e das perguntas, que uma nova percepção estava sendo construída, um novo mundo das abelhas estava surgindo. O mel já não era a coisa mais importante que a abelha fazia para o planeta e o medo do veneno da abelha foi ficando pequeno frente à sua complexa simplicidade de vida. Abelhas fotografadas na cidade de Areia Branca - SE, foram apresentadas para que os alunos tomassem conhecimento da grande diversidade que existe entre as espécies e o mais importante, saber que essas abelhas existem na sua cidade.

A segunda palestra (Figura 2) aconteceu no dia 08/11/19 e teve como tema: "Abelhas sem Ferrão". No início, para verificar a fixação dos conteúdos da palestra anterior sobre Apis e Polinização, foram lançadas algumas perguntas sobre o tema e todas, foram respondidas pelos alunos presentes, demonstrando que o objetivo estava sendo alcançado, não só pela verificação das respostas certas, mas pelo relato dos alunos sobre a observação das abelhas nas flores. Percebeu-se nesse momento a clareza na compreensão e aprimoramento da visão para esses insetos até então quase invisíveis na sua vida diária.

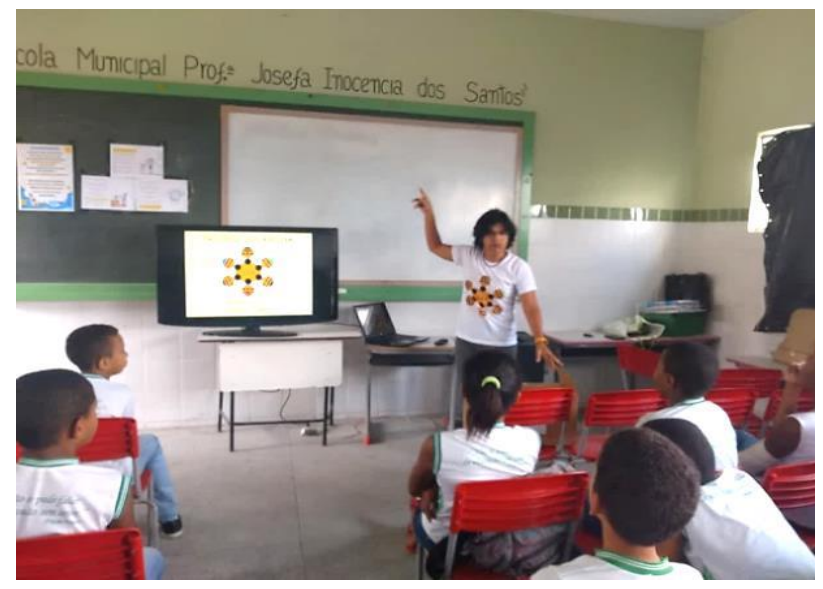

Figura 1. $1^{\text {a }}$. Palestra do SOS abelha na escola municipal Josefa Inocencia dos Santos em Areia Branca Sergipe, 2019

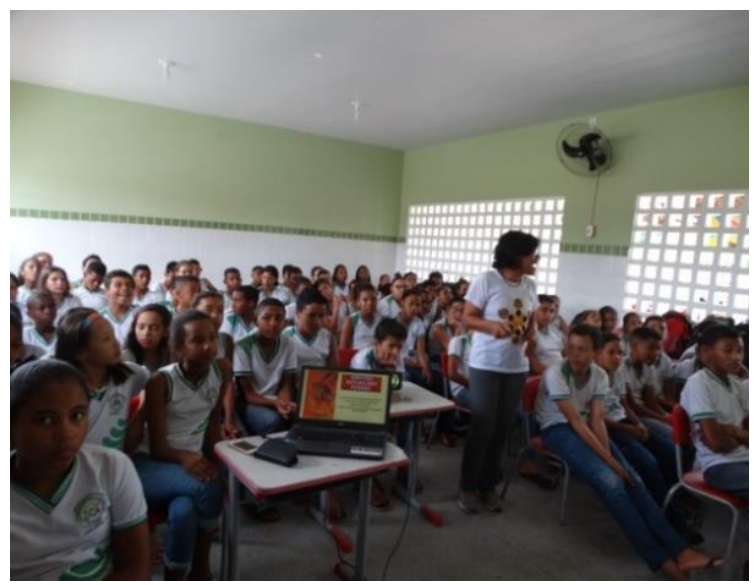

Figura 2. $2^{\text {a }}$. Palestra do SOS abelha na escola municipal Josefa Inocencia dos Santos em Areia Branca Sergipe, 2019 
A última palestra do subprojeto ocorreu no dia 28/11/19 (Figura 3) teve como tema "Abelhas Solitárias". O mundo das abelhas solitárias é fascinante, encanta, principalmente por realizar todo o seu ciclo de vida sozinha, ou seja, as gerações não se sobrepõem como nas abelhas sociais.

A primeira oficina na escola municipal de Areia Branca ocorreu no dia 04/10/19 como continuação da palestra anterior que mostrou o universo das abelhas. Nessa oficina "Plantar para as abelhas" foi apresentada uma muda com flores da planta Amor Agarradinho (Antigonon leptopus) e em seguida foi distribuída sementes para o plantio. Cada aluno plantou sua semente e etiquetou o local (Figuras 4 e 5) e a sementeira foi levada para uma estufa e ao final do projeto as mudas foram entregues aos alunos para plantio em suas casas. Foram apresentadas aos alunos algumas espécies de abelhas fixadas nas placas de petri. Foi o primeiro contato com abelhas reais e todos ficaram fascinados pela diversidade.

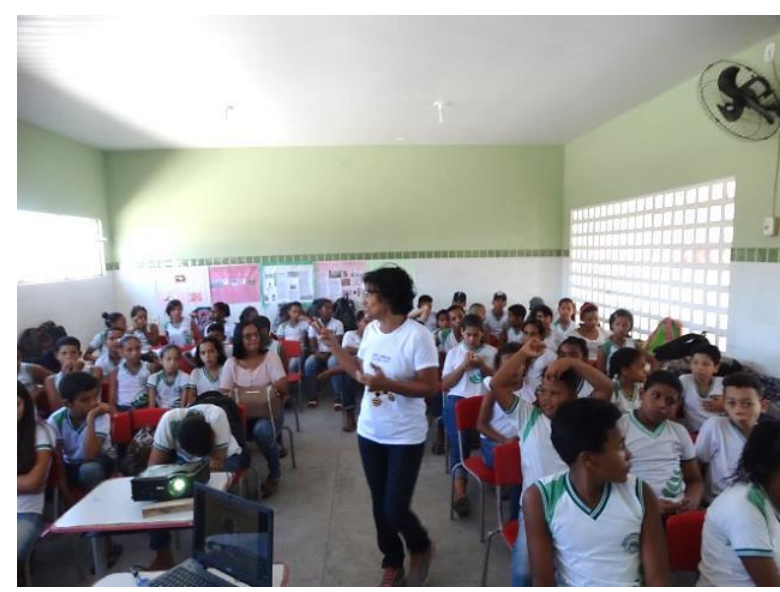

Figura 3. $3^{\text {a }}$. Palestra do SOS abelha na escola municipal de Areia Branca - Sergipe, 2019.

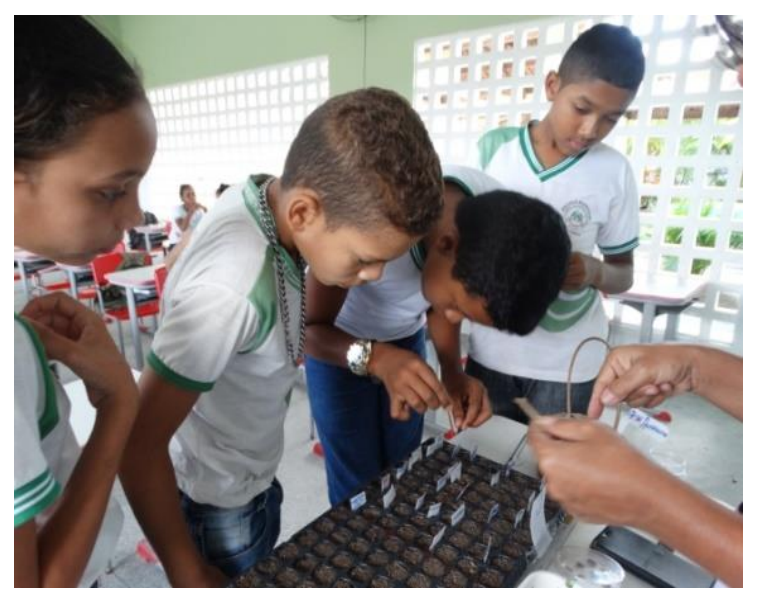

Figura 4. Plantando na $1^{a}$ Oficina na Escola Municipal Josefa Inocencia dos Santos em Areia Branca-Sergipe, 2019.

A segunda oficina do subprojeto na escola com o tema: "Confecção de Iscas para abelhas solitárias" aconteceu no dia 14/11/19 e foi agitada (Figura 6), primeiro porque os alunos já estavam adaptados à presença da palestrante e segundo, foi uma atividade prática em grupo, com duas turmas juntas, no qual cada grupo havia 4 ou 5 componentes para confeccionarem uma isca. Mesmo com a instrução de que todos deviam participar, nem sempre isso foi possível, mas para contornar o problema e finalizar a isca fui a cada grupo e perguntava quem não tinha participado incumbindo o integrante de colocar o atrativo líquido na isca. Foi uma forma de todos realmente participarem da oficina.

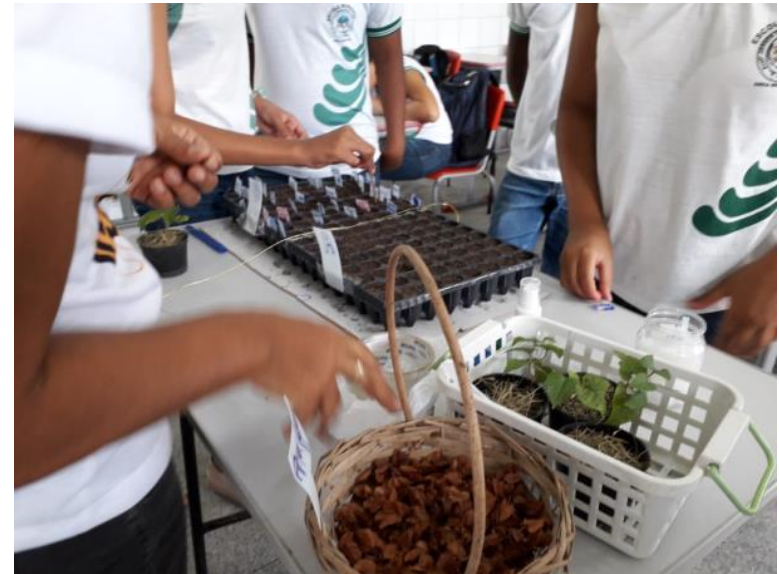

Figura 5. Sementeira na $1^{\text {a }}$ Oficina na escola na Escola Municipal Josefa Inocencia dos Santos em Areia Branca-Sergipe, 2019.

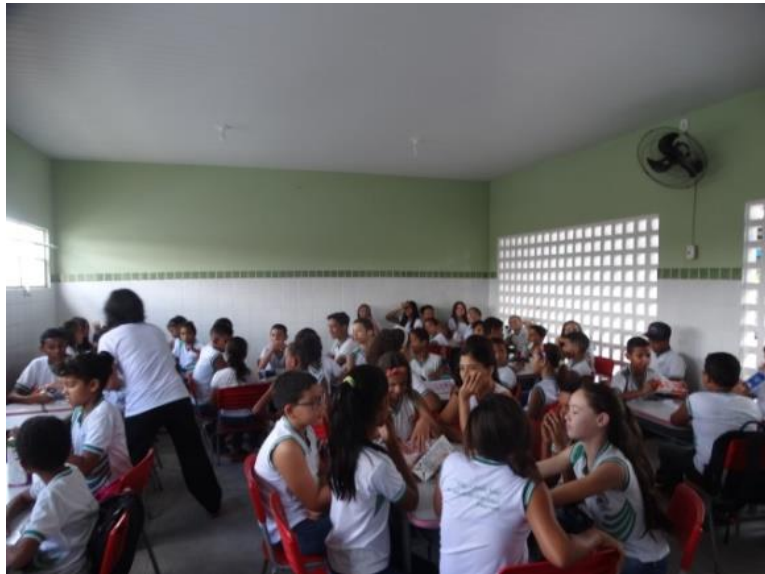

Figura 6. Oficina iscas para ASF na Escola Municipal Josefa Inocencia dos Santos em Areia BrancaSergipe, 2019.

A terceira e última oficina, a mais aguardada de todo o subprojeto denominada "Construção de ninhos de argila para abelhas solitárias" aconteceu no dia 29/11/19 e foi um desafio por conta do número de alunos (Figura 7). A oficina teve como objetivos principais: fazer com que os participantes conheçam 
um pouco das abelhas solitárias, através de fotos, de ninhos em materiais diversos; explicar a importância do pasto apícola, com troca e doação de sementes e por fim, construir um abrigo de argila para as abelhas (Figura 8).

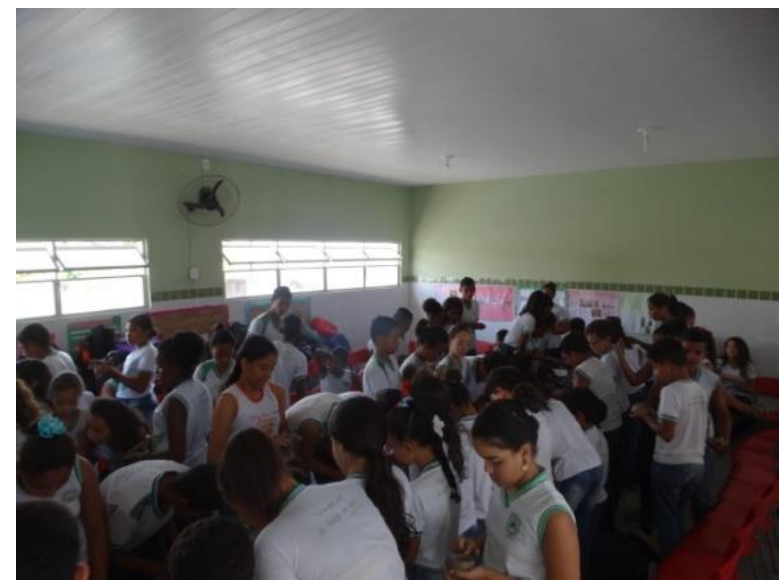

Figura 7. $3^{\mathrm{a}}$ Oficina de argila para abelhas solitárias na Escola Municipal Josefa Inocencia dos Santos em Areia Branca-Sergipe, 2019.

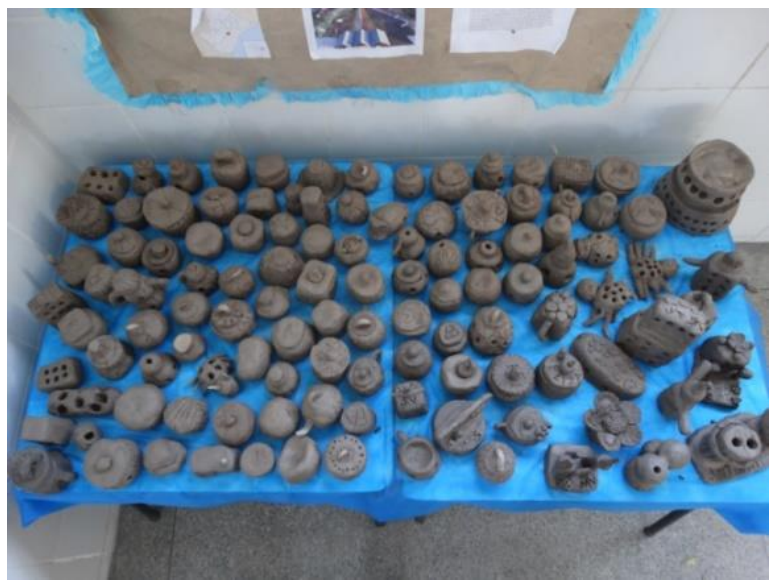

Figura 8. Ninhos de argila para abelhas solitárias confeccionados na $3^{\mathrm{a}}$ oficina na Escola Municipal Josefa Inocencia dos Santos em Areia Branca-Sergipe, 2019.

O último evento foi o encerramento do projeto, que ocorreu no vão central da Escola Municipal de Areia Branca - Sergipe (Figura 9). Para contextualizar os quatro meses de trabalho, foram expostos banners com fotografias das seis atividades (palestras e oficinas) e três mesas: uma com as mudas plantadas na primeira oficina, outra com os ninhos de argila da terceira oficina e por último, uma mesa com as sacolinhas de brinde contendo uma garrafinha com $80 \mathrm{~g}$ de mel de Apis, um saquinho de balas de mel, um folder sobre abelhas e um papel com a seguinte pergunta: "O que você mais gostou no projeto?" Após discursos e fotos, os alunos receberam a muda, o ninho e a sacola de brinde (Figura 10).

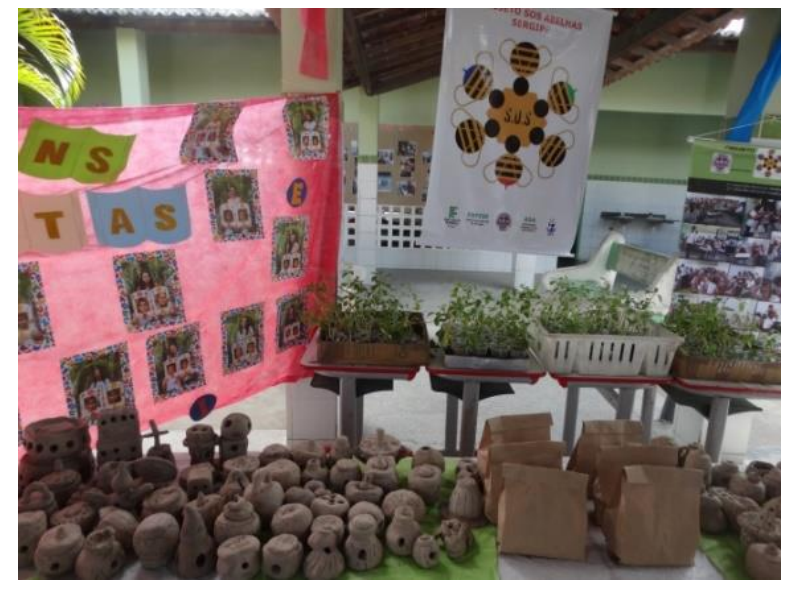

Figura 9. Exposição das oficinas no encerramento do subprojeto SOS abelhas, na Escola Municipal Josefa Inocencia dos Santos, no município de Areia Branca-Sergipe, 2019.

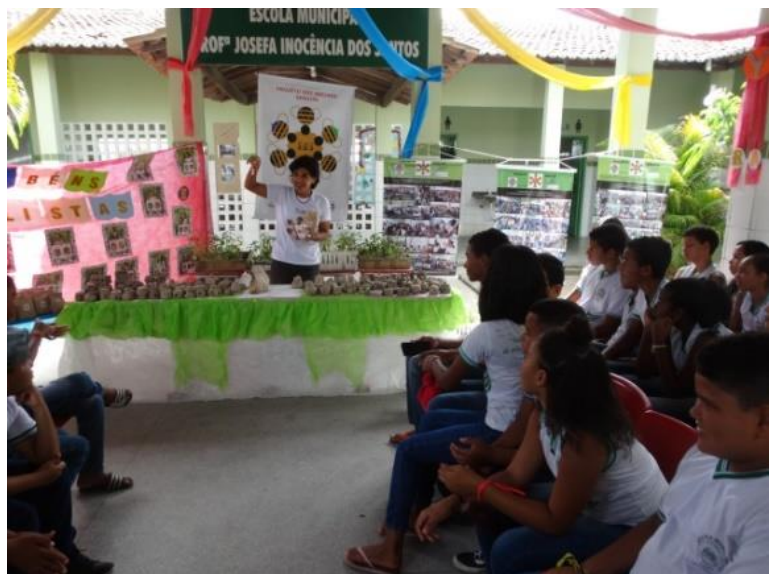

Figura 10. Encerramento do subprojeto SOS abelhas: conhecer para preservar, com os alunos da Escola Municipal Josefa Inocencia dos Santos, no município de Areia Branca-Sergipe, 2019.

Diante das atividades desenvolvidas no SOS abelhas em todo o Estado de Sergipe, ficou evidente para a executora, que toda a comunidade como um todo, pouco sabiam sobre a diversidade das abelhas existente na nossa região. A referência sempre era "aquela" abelha que só produz mel e que é perigosa por possuir ferrão. Foi constatado que havia quase nenhum conhecimento sobre a existência de abelhas sem ferrão e muito menos sobre a existência das abelhas solitárias. Esse fato não foi isolado, foi uma constante em todos os eventos realizados no estado com alunos de todos os níveis educacionais, desde o ensino fundamental até o ensino superior.

Com as palestras e oficinas, os participantes aprenderam de forma lúdica, a importância desses insetos para o meio ambiente, tiveram consciência que as abelhas estão no seu jardim, no seu quintal, 
na sua rua e que elas não apresentam o risco que elas imaginavam. Segundo o relato dos professores, o projeto extrapolou os muros da escola, foi a percepção que tiveram, mediante as questões que os alunos traziam de casa referentes às abelhas e ao meio ambiente. A práxis desconstruiu conceitos errôneos e contribuirá de forma significativa para a preservação das espécies. A educação ambiental deve fazer parte dos currículos da educação fundamental, pois é dever do Estado criar cidadãos compromissados com o meio ambiente.

No decorrer do ESO, o projeto foi solicitado para atender a diversos públicos e naturalmente o conteúdo e a forma de apresentação seria modificada, mas com a constatação ao interagir com diversas pessoas no Congresso de Bem Estar Animal que ocorreu na UFS/São Cristóvão em agosto de 2019, onde foi percebido que quase ninguém conhece sobre abelhas com ferrão, sem ferrão e muito menos abelhas solitárias, foi decido utilizar a mesma apresentação, bem como a mesma didática ao passar o referido conteúdo e o resultado foi o esperado, as palestras elaboradas para o ensino fundamental menor, atenderam perfeitamente a todos os públicos.

Os alunos da Escola me intitularam "A Veterinária das Abelhas", ao mencionar o fato aos colegas do curso, era perceptível a surpresa da maioria. A profissão de Médico Veterinário está além da visão curativa que a sociedade concebe há décadas. Ser veterinário é cuidar de todos os seres vivos do planeta e do próprio planeta. Espero que esse trabalho de conclusão de curso, de alguma forma, incentive os futuros médicos veterinários a ter uma visão mais ampla dessa profissão tão importante para o país.

Na manhã do dia do encerramento do subprojeto na escola municipal em Areia Branca-Sergipe, junto com a sacolinha de brindes fora colocado um pedacinho de papel com a pergunta: "O que você mais gostou no projeto?" e pedi para pensarem sobre essa frase. Juntando os materiais que havia levado, vi que esqueci dois banners, liguei para a diretora avisando que a tarde iria pegar. Quando entrei na secretaria fui direcionada para a sala do $5^{\circ}$ ano, onde a professora Elisângela Rodrigues Cruz Braz sorrindo, me entregou várias cartinhas dos seus alunos. Ao ler cada uma, constatei que a semente da preservação das abelhas foi plantada (Figura 11).

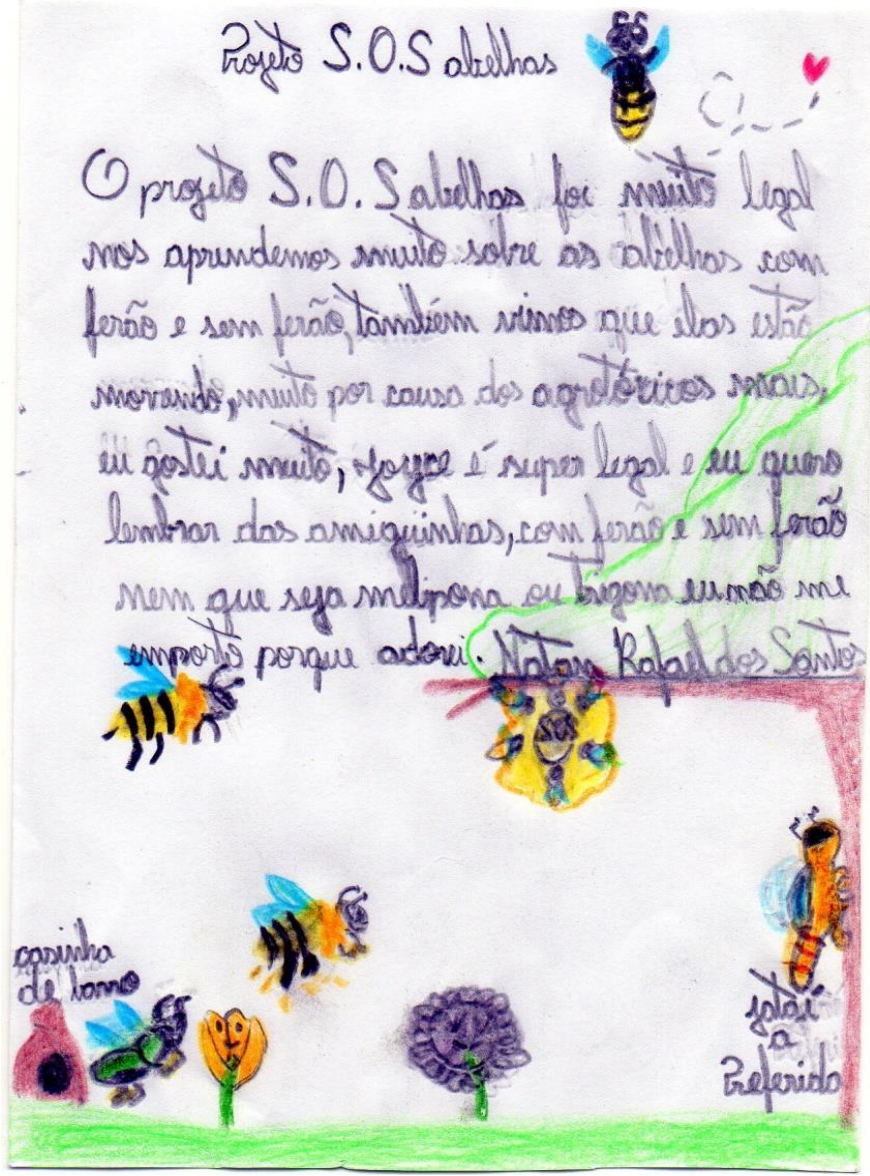

Figura 11. Carta de um aluno da Escola Municipal Josefa Inocência dos Santos, no município de Areia Branca-Sergipe, 2019. 


\section{Conclusão}

A inclusão da educação ambiental nas escolas trouxe resultados significativos ao projeto SOS abelhas do CBMSE, que poderá ser utilizado como base para que outros Estados da federação, graduandos ou profissionais possam desenvolver ações similares em escolas, institutos, associações e outros locais que multiplicam conhecimentos. A práxis é uma ferramenta indispensável na consolidação da educação ambiental e na preservação das abelhas.

\section{Referências}

Abrasco 2019. Disponível em: https://www.abrasco.org.br/site/eventos/congresso-brasileiro-de-saudecoletiva/lancamento-de-nova-producao-do-dossie-agrotoxicos/35441/ acessado em 14/12/2019.

Alves-Dos-Santos, I. 2002. A vida de uma abelha solitária. Revista Ciência hoje 179:60-62.Disponível em: http://portal.cfmv.gov.br/pagina/index/id/67/secao/5. Acesso em 12/12/2019.

Corpo De Bombeiros Militar De Sergipe (CBMSE) 2019. Disponível em: https://www.cbm.se.gov.br/noticias. Acesso em 12/12/2019.

Freire, Paulo. Pedagogia da Autonomia. Saberes necessários à prática educativa. São Paulo: Paz e Terra, 1996. 148p.

Sorrentino, M.;Traiber, R.;Mendonça, P. \& Erraro, E. A. J. 2005. Educação Ambiental como política pública. Educação e Pesquisa, São Paulo, v.1, n. 2, p. 285-299. https://doi.org/10.1590/s1517$\underline{97022005000200010}$

\section{Histórico do artigo:}

Recebido: 10 de fevereiro, 2020.

Aprovado: 16 de março, 2020.

Disponível online: 23 de novembro, 2020. Licenciamento: Este artigo é publicado na modalidade Acesso Aberto sob a licença Creative Commons
Atribuição 4.0 (CC-BY 4.0), a qual permite uso irrestrito, distribuição, reprodução em qualquer meio,
desde que o autor e a fonte sejam devidamente creditados. 